\title{
DIFFERENCES BETWEEN SPRING WHEAT CULTIVARS IN EARLY GROWTH
}

\author{
C. J. T. SPITTERS ${ }^{1 *}$ and TH. KRAMER ${ }^{2}$ \\ ${ }^{1}$ Department of Theoretical Production Ecology, Agricultural University, P. O. Box 430, $6700 \mathrm{AK}$ \\ Wageningen, the Netherlands \\ ${ }^{2}$ Institute of Plant Breeding, Agricultural University, Wageningen, the Netherlands
}

Received 2 January 1985

INDEX WORDS

Triticum aestivum, wheat, growth analysis, relative growth rate, selection.

SUMMARY

Twelve spring wheat cultivars were grown as isolated plants in the field and their pre-anthesis growth was interpreted in terms of plant growth analysis. Relative growth rate (RGR) decreased steadily with time due to a decline of leaf area per unit plant weight (LAR), which could be explained by the reduction of the portion of leaf weight in total plant weight (LWR). Growth per unit leaf area (NAR) and leaf area per unit leaf weight (SLA) changed only little with time.

Differences between cultivars for NAR and LAR were of similar magnitude: both $8 \%$ when measured by the genetic coefficient of variation. Because both quantities were negatively correlated, the genetic variation of RGR was only $5 \%$. Genetic variation for LWR and SLA were also of similar size, both about $4 \%$. Estimates of genetic variances and covariances based on cultivar means appeared to be biased strongly when the error variation of the means was neglected.

Special attention is paid to the methodology of plant growth analysis.

\section{INTRODUCTION}

During the early phases of growth, plants are standing free and do not yet compete with each other. The rate of early growth determines time of canopy closure and with that beginning of full light interception. The rate of early growth affects therefore crop yield, especially in crops grown at low plant densities like maize and sugar beet (SiBma, 1977).

In a mixed population, composed of different genotypes, the rate of early growth of a genotype determines the share in the total leaf area that this genotype acquires at onset of competition. This share is a main determinant of its competitive ability in mixture (SPITTERs, 1984a, b). Knowledge about genetic differences for early growth contributes therefore to a better understanding of competitive differences between genotypes and how these differences confound with selection of plants from segregating populations.

* Present address: Foundation for Agricultural Plant Breeding, SVP, P.O. Box 117, NL-6700 AC Wageningen, the Netherlands. 
To avoid the bias from intergenotypic competition it has often been suggested to apply selection to single, free-grown plants. Growth analysis of such isolated plants is needed to derive which types of plants benefit from this way of selection. The ratios between the plant weight of different genotypes change in course of the growing season because of genetic differences in relative growth rate (RGR). As time proceeds, these plant weight ratios deviate more and more from their ratios in seedling weight. The time course of the correlation between the biomass of a genotype and its seedling weight was calculated, and interpreted in terms of differences in RGR, for a set of 12 spring wheat cultivars grown in isolation (SPITTERS \& KRAMER, 1985). In the present paper, the genetic differences in RGR will be analyzed in more detail by partioning RGR into its components. The analysis is restricted to the period until anthesis because for the period of grain filling there were too few experimental data. Experimental details have been given in the preceding paper and in the Appendix.

First, methods of estimating the growth components are discussed. Subsequently, we consider the time trends of these components and their genetic variation. Methods of plant growth analysis were discussed by CAUSTON \& VENUS (1981) and HUNT (1982). The analyses have been applied to a set of 12 varieties of spring wheat and amended, like in the preceding paper, for comparison of different genotypes and estimating population characteristics as genetic variances and covariances.

\section{METHODS OF GROWTH ANALYSIS}

The relative growth rate can be subdivided according to

$$
\begin{aligned}
& \frac{\mathrm{dW} / \mathrm{dt}}{\mathrm{W}}=\frac{\mathrm{dW} / \mathrm{dt}}{\mathrm{L}_{\mathrm{A}}} \times \frac{\mathrm{L}_{\mathrm{A}}}{\mathrm{W}}=\frac{\mathrm{dW} / \mathrm{dt}}{\mathrm{L}_{\mathrm{A}}} \times \frac{\mathrm{L}_{\mathrm{W}}}{\mathrm{W}} \times \frac{\mathrm{L}_{\mathrm{A}}}{\mathrm{L}_{\mathrm{W}}} \\
& \mathrm{RGR}=\mathrm{NAR} \times \mathrm{LAR}=\mathrm{NAR} \times \mathrm{LWR} \times \mathrm{SLA}
\end{aligned}
$$

where $\mathrm{W}$ represents plant dry weight, $\mathrm{L}_{\mathrm{A}}$ leaf area and $\mathrm{L}_{\mathrm{W}}$ leaf weight, all per plant at time t. The 'net assimilation rate' (NAR) is the dry matter increment per unit leaf area per unit time and measures the difference between gross assimilation and respiration. The 'leaf area ratio' (LAR) is the amount of leaf area which is formed per unit plant weight. So it reflects the influence of the morphology of the plant on its relative growth rate. LAR may be partitioned into 'specific leaf area' (SLA), a measure of leaf thickness, and into 'leaf weight ratio' (LWR), representing that part of total plant weight that is invested in leaves. The inverse of SLA is called 'specific leaf weight' (SLW).

The growth components may be estimated (a) for each interval between two successive harvests, (b) for the early phase showing exponential growth with a linear regression of $1 \mathrm{n} \mathrm{W}$ on time (first degree polynomial) over some harvests and (c) from functions fitted to the time courses of $\mathrm{W}, \mathrm{L}_{\mathrm{A}}$ and $\mathrm{L}_{\mathrm{W}}$.

(a) For the interval $t_{1}-t_{2}$, we obtain

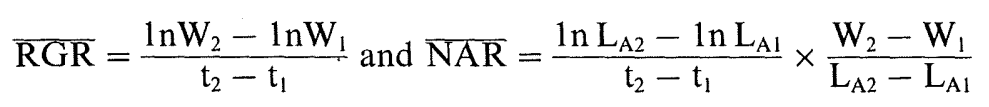

The equation of $\overline{\mathrm{NAR}}$ assumes a linear relation between $\mathrm{W}$ and $\mathrm{L}_{\mathrm{A}}$ over the studied 
time interval (RADFORD, 1967). LAR, LWR and SLA are best represented by their values at the individual harvests. When mean values are desired, simple arithmetical means satisfy.

(b) In the first few weeks after emergence, plants grow approximately exponentially:

$\mathrm{W}=\mathrm{W}_{0} \cdot \mathrm{e}^{\mathrm{R}_{\mathrm{W}} \cdot \mathrm{t}}$ and $\mathrm{L}_{\mathrm{A}}=\mathrm{L}_{\mathrm{A}_{0}} \cdot \mathrm{e}^{\mathrm{R}_{\mathrm{A}} \cdot \mathrm{t}}$

where $R_{W}$ and $R_{A}$ are the relative growth rates for plant weight and leaf area, respectively. The constants $\mathrm{W}_{0}$ and $\mathrm{L}_{\mathrm{A}_{0}}$ may be estimated from linear regression of $1 \mathrm{nW}$ and $1 \mathrm{~nL}_{\mathrm{A}}$ against time. The growth components are estimated as

$\overline{R G R}=R_{W}$ and $N A R_{t}=\frac{W_{O}}{L_{A 0}} R_{W} e^{\left(R_{W}-R_{A}\right) t}$

with the most reliable estimate of $\mathrm{NAR}_{t}$ obtained for $\mathrm{t}$ being the central time of the data set. For LAR, LWR and SLA see (a).

(c) The growth components may also be derived from the functions fitted to the time courses of $1 \mathrm{n} W, \ln \mathrm{L}_{\mathrm{A}}$ and $1 \mathrm{n} \mathrm{L}_{\mathrm{W}}$, which supplies instantaneous values for the growth components. Equations were given by HUNT (1982, p. 56).

For more details the reader is referred to RADFORD (1967), CAUSTON \& VENUS (1981), and HunT (1982).

RESULTS

Time trends of the growth components. The time courses of the growth components, calculated according to the three different methods, are plotted in Fig. 1. The values are represented on a relative scale in order to compare time trends with each other. The estimates of RGR and NAR based on pairs of subsequent harvests are difficult to interpret due to their large random variation. However, estimates based on the functions fitted to the primary data allow conclusions (Fig. 1).

RGR decreased steadily with time. The decrease of RGR ran parallel to the decrease of the leaf area per unit plant weight (LAR), whereas the growth per unit leaf area (NAR) changed only little. The decrease of LAR was almost entirely accounted for by a reduced portion of the leaf weight in the total plant weight. This decrease in LWR was due to the increasing fraction of the assimilates going to the stems (see Appendix). Leaf thickness seemed to be reduced somewhat in time, but the small increase of SLA can have retarded the decrease of LAR only a little.

The presence of photosynthesizing ears after day 60 induces a slight overestimation of NAR as NAR was expressed per unit leaf area. At anthesis, the effective area of the ears was $1 / 7$ th of the leaf area. Also the contribution of leaf sheaths to assimilation was neglected.

Genetic variation of the growth components. The genetic variance of each of the growth components was estimated from an analysis of variance per harvest (LAR, LWR, SLW) or from that per interval between two harvests (RGR, NAR) analogous to the procedure described in SPITTERS \& KRAMER. (1985) for the estimation of the genetic variance of RGR. A dimensionless yardstick of the genetic variation is obtained with 

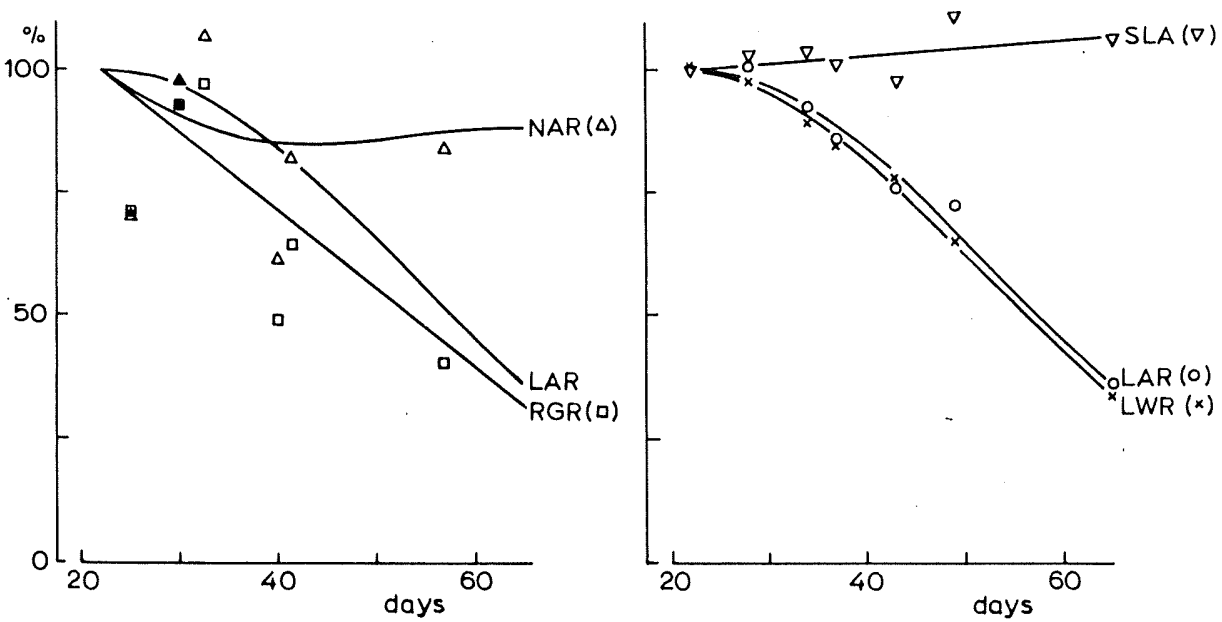

Fig. 1. Time trends up to anthesis of the growth components of isolated plants in the field. Curves were derived from second-degree polynomials fitted to the $1 \mathrm{n}$-transformed data of total weight, leaf weight and leaf area per plant. Data points were obtained per harvest (LAR, LWR, SLA), per interval between two harvests (RGR, NAR) or from linear regression over the harvests at day 22, 28, 34, 37 (solid symbols of RGR and NAR). The $100 \%$ levels are $0.201 \mathrm{day}^{-1}$ for RGR, $13.8 \mathrm{~g} \mathrm{~m}^{-2} \mathrm{day}^{-1}$ for NAR, $146 \mathrm{~cm}^{2} \mathrm{~g}^{-1}$ for LAR, $0.691 \mathrm{~g} \mathrm{~g}^{-1}$ for LWR and $211 \mathrm{~cm}^{2} \mathrm{~g}^{-1}$ for SLA.

Time is expressed in days after emergence.

Table 1. Genetic coefficients of variation $\left(\mathrm{CV}_{\mathrm{g}}\right.$ in $\left.\%\right)$ for the growth components. Top section: medians over the period till anthesis in the spring wheat experiment. Bottom section: orders of magnitude supposed to be representative for the variation in vegetative growth parameters among cereal genotypes in breeding nurseries (for references see discussion). Presented are relative growth rate (RGR), net assimilation rate (NAR), leaf area ratio (LAR), specific leaf weight (SLW), leaf weight ratio (LWR), leaf assimilation at light saturation $\left(A_{\max }\right)$, initial light use efficiency $(\varepsilon)$, maintenance respiration $\left(R_{m}\right)$, and light extinction coefficient $(\mathrm{k})$.

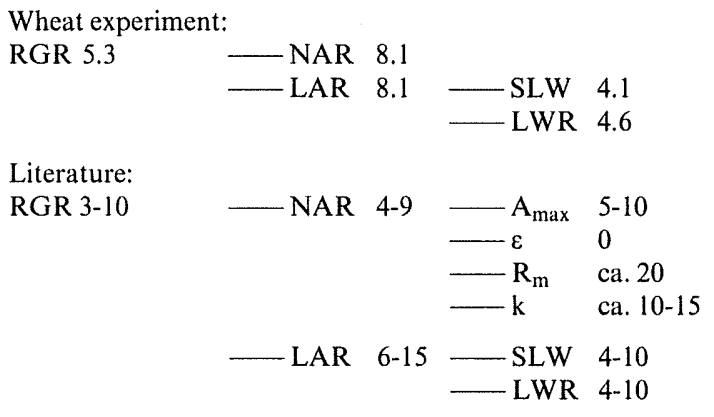

the genetic coefficient of variation $\left(\mathrm{CV}_{\mathrm{g}}\right)$, the square root of the genetic variance expressed relative to the mean of the growth component. The medians of these are given in Table 1.

Genetic correlation between growth components. The correlation between growth components was calculated on the basis of variety means. This was done for the period 
of day 22-37 (four harvests, estimations by Equation 3) and for the period of day 49-65 (two harvests, estimations by Equation 2). From each of these phenotypic correlations $r_{p}$ between two growth components $x$ and $y$, the corresponding genetic correlation was estimated as

$r_{g}=\frac{r_{p} \sqrt{\operatorname{var} p_{x} \cdot \operatorname{var} p_{y}}-r_{e} \sqrt{\operatorname{var}_{x} \cdot \operatorname{var} e_{y}}}{\sqrt{\operatorname{var} g_{x} \cdot \operatorname{var} g_{x}}}$

where the variances refer to phenotypic, genetic and environmental variances. The environmental correlation $r_{e}$ accounts for the interdependence of the error terms of the two growth components and is due to the fact that both growth components are estimated from data collected on the same plants and are sometimes even partly based on the same data. If, for example, due to some random factor, the plant weight $\mathrm{W}_{2}$ is overestimated, both RGR and NAR are inflated (Equation 2), which introduces a positive value of $r_{e}$ between them.

In the literature, comparisons are mostly done on correlations based on variety means. The bias due from random variation in the variety means and interdependence of the error terms is, in general, overlooked. Comparison of the first with the third correlation matrix of Table 2 illustrates that in this way a serious bias may be introduced.

Equation 4 shows that the bias will be largest for the components having a large error variance relative to their genetic variance. RGR and NAR satisfy this condition more than LAR, LWR and SLW, especially when RGR and NAR are estimated by the classical approach. The greater the correlation between the error terms, the larger the bias will be. For example, for day 49-65, the phenotypic correlation between the variety means of RGR and NAR was 0.25 . The phenotypic, genetic and environmental variances were $0.47,0.23$ and $0.24 \times 10^{-4}$ day $^{-2}$ for $R G R$ and $1.59,0.87$ and $0.72 \times 10^{-8} \mathrm{~g}^{2} \mathrm{~cm}^{-4} \mathrm{day}^{-2}$ for NAR, respectively. Equation 4 shows that correction for the random variation in the variety means only and assuming $r_{e}=0$ results in a correlation of 0.48 . When the strong correlation between the error terms is also considered $\left(r_{e}=0.93\right)$, the genetic correlation falls to -0.37 (Table 2). For the other combinations, the environmental correlation had a much lesser effect because that correlation was smaller (second matrix of Table 2 with trends that can be understood from Equations 1 and 2) and because LAR, LWR and SLW had a smaller environmental variance than RGR or NAR. For these other combinations, the estimates of $r_{g}$ with $r_{e}$ involved differed on the average 0.04 points (day 22-37) and 0.05 points (day 49-65) from $r_{\mathrm{g}}$ when $r_{\mathrm{e}}$ was not involved.

In general, it will be sufficient to involve the environmental correlation in the combination of RGR and NAR only. On the other hand, the random variation of the variety means should be taken into account in all combinations. Otherwise, a serious bias is risked (first against third matrix of Table 2). A disadvantage of using Equation 4 is, however, that the confidence interval of the estimate of the correlation coefficient is widened due to the accumulation of the errors of the involved estimated variances and covariances.

Subdividing the varietal differences in $R G R$. The varietal differences in RGR were accounted for by differences in LAR as well as in NAR ( $\mathrm{r}_{\mathrm{g}}^{2}$ in Table 2). The genetic 
N Table 2. Correlations between the growth components for the periods of day 22-37 (above the diagonals) and day 49-65 (below the diagonals). Presented are the phenotypic correlation between variety means, the environmental correlation showing the interdependence of the error terms, and the genetic correlation.

\begin{tabular}{|c|c|c|c|c|c|c|c|c|c|c|c|c|c|c|c|}
\hline & \multicolumn{5}{|c|}{ Phenotypic correlation } & \multicolumn{5}{|c|}{ Environmental correlation } & \multicolumn{5}{|c|}{ Genetic correlation } \\
\hline & RGR & NAR & LAR & LWR & SLW & RGR & NAR & LAR & LWR & SLW & RGR & NAR & LAR & LWR & SLW \\
\hline RGR & & 0.63 & 0.40 & 0.11 & -0.32 & & 0.93 & 0.22 & 0.14 & -0.17 & & 0.45 & 0.50 & 0.11 & -0.39 \\
\hline NAR & 0.25 & & -0.45 & -0.31 & 0.29 & 0.93 & & -0.14 & 0.03 & 0.12 & -0.37 & & -0.58 & -0.41 & 0.35 \\
\hline LAR & 0.55 & -0.66 & & 0.48 & -0.71 & 0.07 & -0.28 & & 0.29 & -0.81 & 0.78 & -0.86 & & 0.50 & -0.73 \\
\hline LWR & 0.51 & -0.60 & 0.90 & & 0.27 & -0.20 & -0.44 & 0.79 & & 0.29 & 0.79 & -0.74 & 0.91 & & 0.26 \\
\hline SLW & -0.26 & 0.37 & -0.55 & -0.14 & & -0.35 & -0.10 & -0.44 & 0.18 & & -0.29 & 0.55 & -0.56 & -0.16 & \\
\hline
\end{tabular}


variation in LAR was relatively of the same size as that in NAR (Table 1). The varietal differences in LAR were brought about by differences in LWR as well as by differences in SLW (Table 2), with the genetic variation of each of these components of similar magnitude.

This contrasted with the change of RGR in time, which was almost completely explained for by a similar change of LAR, which, in its turn, could fully be ascribed to the change of LWR (Fig. 1).

Varieties with a greater LAR had, on average, a higher weight proportion of leaves in the total biomass (greater LWR) and thinner leaves (smaller SLW). Both effects act into the same direction so that the genetic variation of LAR was relatively greater than that of each of its components (Table 1), the more so as the correlation between LWR and SLW was not too strongly negative.

Varieties with a greater NAR had a smaller LAR, partly due to a smaller LWR and partly to a greater SLW (Table 2). The phenomenon that varieties with thicker leaves tend to have a higher assimilation rate per unit leaf area has frequently been found and is due to a correlation between leaf thickness and those anatomical characteristics of the leaf that favour a high assimilation rate per unit leaf area (e.g. PEARCE et al., 1969; Criswell \& SHIBLES, 1971). The strength of the negative correlation between NAR and LWR is surprisingly high for the younger plants. We have no explanation for this. For the older plants, shading between leaves within the plant contribute to such negative relation. The opposite trends of NAR and LAR resulted in a genetic variation of RGR which was relatively smaller than that of each of its components (Table 1).

The study refers to single grown plants. For plants grown at a dense stand, the genetic correlations among the growth components may be different.

DISCUSSION

\section{Classical against functional approach in growth analysis}

In the present paper, two procedures in growth analysis were followed: (a) the 'classical approach' where the growth components (RGR, etc.) were estimated per harvest or per interval between two harvests, and (b) the 'functional approach' where they were estimated from the functions fitted to the primary data of total weight, leaf weight and leaf area per plant.

The main advantages of the functional approach are that estimates of the components may be obtained for any desired time step and that their confidence intervals are relatively narrow because the information of all harvests is used in the fitted function. On the other hand, the classical approach supplies estimates at the times of harvest only (LAR, LWR and SLA) or for the mean over two harvests (RGR and NAR) with the confidence intervals of especially RGR and NAR being rather wide. These disadvantages are avoided by drawing hand-smoothed curves through the primary data and calculating the growth components by the classical approach from these curves. This method has, however, the disadvantage of lack of statistical objectivity.

HUNT (1982, p. 54) claimed not less than 12 advantages of the functional approach. That suggests a general superiority of this method. However, there are some disadvan- 
tages too. We have already discussed several of them (SPITters \& Kramer, 1985) and some will now be mentioned.

The advantage of fitted functions that each point of the curve carries the information of all harvests is, at the same time, also a disadvantage. The data points are, in that way, no longer independent of each other, so their error terms are confounded. That may bias or hamper statistical analysis. This holds especially for the estimation of correlation coefficients between and within the functions. It biases also the relation between calculated instantaneous values of RGR and environmental variables like irradiation and temperature.

Lack of fit in the two functions fitted to the time series of the variables $\mathrm{L}$ and $\mathrm{W}$ separately accumulates in the estimation of their ratio L/W. It may then be preferable to calculate $\mathrm{L} / \mathrm{W}$ from the primary data at each harvest and fit the function to the time trend of L/W (e.g. Fig. 2 in SpITTERS \& Kramer, 1985).

The frequent output of the growth components obtainable with a fitted function proceeds much more regularly in time than the sparse data points obtained with the . classical approach. That regularity brings a risk of being tricked into an over-appraisal of the accuracy and into an obscurance of the lack of fit.

The functional approach assumes that the fitted function gives an accurate description of the progress of the studied plant attribute in time. For an accurate description a large number of harvests is required, although the sample size of each harvest may be rather small. When a long time period is considered the use of advanced techniques like splined regression (HunT \& PARsons, 1977) is required. The 10 harvests involved in this experiment formed too small a number to apply those techniques. The large number of harvests as well as the required mathematics will be a problem for the average experimentalist comparing varieties.

In conclusion, the functional approach in growth analysis shows several important benefits. The classical approach, however, is also of value. Especially as it is straightforward, relatively simple and requires less computing facilities. Moreover, it does not introduce an interdependence of the errors of the output data provided that RGR's and NAR's of subsequent harvest intervals have no input data in common. It is advisable to apply both methods simultaneously.

Plant growth analysis in terms of RGR and its components is directed towards explaining growth from (a) amount of leaf area present, a morphological component and (b) average production per unit leaf area, mainly a physiological component. This partitioning makes only sense if growth is related about linearly to leaf area. That holds for isolated, free-growing plants, especially when light is the main growth limiting factor. It holds also for genotypes growing in mixture with other genotypes as the growth of a genotype in mixture depends largely on its share in the total leaf area. However, it does not hold for closed monocrops. A closed canopy intercepts nearly all of the incident light so that an increase of leaf area does not result in an additional light interception. The morphological component (LAR) is then of no importance for growth. Moreover, the assimilation per unit soil area, instead of that per unit leaf area (NAR), tends to be constant in time.

Interpretation in terms of relative growth rates implies an interpretation in terms of relative, percentage effects. This is especially useful during exponential growth 
where the percentage increment is constant and in mixture where the percentage differences between the genotypes tend to be maintained in time (SPITTERS, 1984a). A closed green crop surface shows a more or less linear growth (SiBmA, 1968) so that the absolute differences between monocrops tend to be maintained during their grand period of growth.

In conclusion, the former way of plant growth analysis is useful only for isolated plants and for plants growing in mixture but it does not make sense for closed monocrops.

\section{A simple model for $R G R$ of isolated plants}

For a better understanding of the genetic variation for RGR, it is necessary to analyse this quantity in more detail. Equation 1 gives the partitioning

$\mathrm{RGR}=\mathrm{NAR} \times \mathrm{LAR}=\mathrm{NAR} \times \mathrm{LWR} \times \mathrm{SLA}$

Net assimilation rate equals gross assimilation rate $\mathrm{A}$ minus maintenance respiration $\mathrm{R}_{\mathrm{m}}$, both expressed in $\mathrm{g} \mathrm{CH}_{2} \mathrm{O} \mathrm{m}^{-2}$ leaf $\mathrm{d}^{-1}$, multiplied by the factor $\mathrm{E}_{\mathrm{c}}$, representing the efficiency with which the assimilates $\left(\mathrm{CH}_{2} \mathrm{O}\right)$ are converted into structural dry matter:

$\mathrm{NAR}=\mathrm{E}_{\mathrm{c}}\left(\mathrm{A}-\mathrm{R}_{\mathrm{m}}\right)$

For well-growing plants, $\mathrm{A}$ is determined by the amount of light absorbed and the photosynthetic characteristics of the leaves. Light transmission through a canopy decreases exponentially with leaf area index LAI, so that the amount of light absorbed per unit soil area becomes

$I_{a b s}=\left(1-e^{-k \times L A I}\right) I_{0}$

where $\mathrm{I}_{\mathrm{o}}$ is the incident light flux (in $\mathrm{J} \mathrm{m}^{-2}$ soil $\mathrm{d}^{-1}$ ) and $\mathrm{k}$ is the extinction coefficient which is for small cereals in the order of 0.6-0.7. Leaf area index (in $\mathrm{m}^{2}$ leaf $\mathrm{m}^{-2}$ soil) is the product of plant weight $\mathrm{W}$, leaf area ratio LAR and plant density $\mathrm{N}$ :

$\mathrm{LAI}=\mathrm{W} \times \mathrm{LAR} \times \mathrm{N}$

This approach assumes that leaf area is uniformly distributed over the soil area. However, especially at wide spacings, leaf area is clustered within individual plants. When there is significant self-shading within the plant, allowance should be made for this. For that purpose a plant may be represented by a cylinder within which the leaf area is distributed homogeneously. Under an isotropic hemisphere, the area effectively occupied by the plant $\left(\mathrm{S}\right.$ in $\mathrm{m}^{2}$ plant $\left.^{-1}\right)$ equals the upper surface of the cylinder $\left(\pi \mathrm{r}^{2}\right)$ plus half the mantle surface $\left(\frac{1}{2} \times 2 \pi \mathrm{rh}\right)$. Leaf area index is then defined as the leaf area of the plant (LAR $\times \mathrm{W}$ ) divided by the effectively occupied area (S). Light absorption per plant is then calculated analogous to Equation 6 (see van GeRWeN et al., 1986).

The daily absorbed amount of light per unit soil area ( $\mathrm{I}_{\text {abs }}$ in Equation 6) is converted into an average hourly intensity per unit leaf area:

$I_{a b s}^{\prime}=I_{a b s} /(D \times L A I)$ 
where D is the effective daylength in hours (GoudriaAN, 1982). Substitution of the absorved light flux $\mathrm{I}_{\mathrm{abs}}^{\prime}$ into the hyperbolic assimilation-light response curve and multiplication with the effective daylength gives the daily gross assimilation in $\mathrm{g} \mathrm{CH}_{2} \mathrm{O}$ $\mathrm{m}^{-2}$ leaf $\mathrm{d}^{-1}$ :

$\mathrm{A}=\frac{30}{44} \mathrm{D} \frac{\varepsilon \times \mathrm{I}_{\mathrm{abs}}^{\prime}}{\varepsilon \times \mathrm{I}_{\mathrm{abs}}^{\prime}+\mathrm{A}_{\max }} \mathrm{A}_{\max }$

where $A_{\max }$ is leaf assimilation at light saturation and $\varepsilon$ is the initial slope of the curve, i.e. the light utilization efficiency at low light. In small cereals, $\mathrm{A}_{\max }$ is about $4 \mathrm{~g} \mathrm{CO}_{2}$ $\mathrm{m}^{-2}$ leaf $\mathrm{h}^{-1}$ and $\varepsilon$ is $12 \times 10^{-6} \mathrm{~g} \mathrm{CO}_{2} \mathrm{~J}^{-1}$ absorbed at $20^{\circ} \mathrm{C}$. The term $30 / 44$ accounts for the conversion of absorbed $\mathrm{CO}_{2}$ into $\mathrm{CH}_{2} \mathrm{O}$. This assumes that light is the main limiting factor and that growth is limited by the size of the carbohydrate source rather than by the sink capacity of the plant.

Maintenance respiration is proportional to the amount of dry weight present. PENNING DE VRIES \& VAN LAAR (1982) suggest for leaf blades a maintenance requirement of $0.03 \mathrm{~g} \mathrm{CH}_{2} \mathrm{O} \mathrm{g}^{-1}$ dry weight $\mathrm{d}^{-1}$ at $25^{\circ} \mathrm{C}$ and about half of this amount for the other organs. Weight of leaf blades $\mathrm{W}_{1}$ and weight of other organs $\mathrm{W}_{\mathrm{n}}$ are therefore distinguished. The maintenance respiration in $\mathrm{g} \mathrm{CH}_{2} \mathrm{O} \mathrm{m}^{-2}$ leaf $\mathrm{d}^{-1}$ is derived to be

$\mathrm{R}_{\mathrm{m}}=\frac{0.015 \mathrm{~W}_{1}+0.0075 \mathrm{~W}_{\mathrm{n} 1}}{\mathrm{SLA} \times \mathrm{W}_{1}}=\frac{0.0075}{\mathrm{SLA}}\left(\frac{\mathrm{LWR}+1}{\mathrm{LWR}}\right)$

where the maintenance requirements were halved $\left(\mathrm{Q}_{10}=2\right)$ to adapt them to an average temperature of $15^{\circ} \mathrm{C}$.

The carbohydrates remaining after subtraction of cost of maintenance are converted into structural dry matter with a conversion efficiency $\mathrm{E}_{\mathrm{c}}$ of about $0.70 \mathrm{~g}$ dry weight $\mathrm{g}^{-1} \mathrm{CH}_{2} \mathrm{O}$ (Penning de VRIes \& Van LaAR, 1982).

As an example, NAR and RGR are calculated with the above procedure for the third decade of May in the presented field experiment. The status of the plants is characterized by quantities observed 37 days after emergence: $W=0.70 \mathrm{~g} \mathrm{plant}^{-1}$, LAR $=0.0126 \mathrm{~m}^{2}$ leaf $\mathrm{g}^{-1}$ plant, $\mathrm{SLA}=0.0213 \mathrm{~m}^{2}$ leaf $\mathrm{g}^{-1}$ leaf, $\mathrm{LWR}=0.59 \mathrm{~g}$ leaf $\mathrm{g}^{-1}$ plant (Appendix). Half of the total global radiation is photosynthetically active (400-700 nm) so that for the third decade of May $\mathrm{I}_{\mathrm{o}}=10 \times 10^{6} \mathrm{Jm}^{-2} \mathrm{~d}^{-1}$ (Appendix). The effective daylength in this period is $13.8 \mathrm{~h}$. Typical values for the assimilation-light response of wheat are $\mathrm{A}_{\max }=4 \mathrm{~g} \mathrm{CO}_{2} \mathrm{~m}^{-2}$ leaf $\mathrm{h}^{-1}$ and $\varepsilon=12 \times 10^{-6} \mathrm{~g} \mathrm{CO}_{2} \mathrm{~J}^{-1}$ and for light extinction $\mathrm{k}=0.6$.

For the harvest at day 37 , plants were grown at a density of 44 plants $\mathrm{m}^{-2}$. This gives for LAI a value of $0.70 \times 0.0126 \times 44=0.39 \mathrm{~m}^{2}$ leaf $\mathrm{m}^{-2}$ soil. On the basis of Equations 6 and 8, $\mathrm{I}_{\mathrm{abs}}^{\prime}=0.39 \times 10^{6} \mathrm{Jm}^{-2}$ leaf $\mathrm{h}^{-1}$ is calculated for the average light absorption. Substitution into Equation 9 gives a gross assimilation rate of 20.3 $\mathrm{g} \mathrm{CH}_{2} \mathrm{O} \mathrm{m}^{-2}$ leaf d $\mathrm{d}^{-1}$. Equation 10 gives for the cost of maintenance $\mathrm{R}_{\mathrm{m}}=0.9 \mathrm{~g} \mathrm{CH}_{2} \mathrm{O}$ $\mathrm{m}^{-2}$ leaf $\mathrm{d}^{-1}$. Hence, NAR amounts to $0.70 \times(20.3-0.9)=13.6 \mathrm{~g}$ dry weight $\mathrm{m}^{-2}$ leaf $\mathrm{d}^{-1}$. Multiplication with LAR gives RGR $=0.17 \mathrm{~d}^{-1}$. These predicted values are in good agreement with the observed values at day 37 for which was interpolated NAR $=11.9 \mathrm{~g} \mathrm{~m}^{-2} \mathrm{~d}^{-1}$ and $\mathrm{RGR}=0.15 \mathrm{~d}^{-1}$ (Fig. 1). This result shows that the model is realistic. 


\begin{tabular}{|c|c|c|c|c|c|c|c|c|c|c|c|c|}
\hline & \multicolumn{4}{|c|}{ RGR $\left(\right.$ day $\left.^{-1}\right)$} & \multicolumn{2}{|c|}{ NAR $\left(\mathrm{g} \mathrm{m}^{-2}\right.$ day $\left.^{-1}\right)$} & \multicolumn{2}{|c|}{$\operatorname{LAR}\left(\mathrm{cm}^{2} \mathrm{~g}^{-1}\right)$} & \multicolumn{2}{|c|}{$\operatorname{LWR}\left(\mathrm{g} \mathrm{g}^{-1}\right)$} & \multicolumn{2}{|c|}{$\operatorname{SLW}\left(\mathrm{mg} \mathrm{cm}^{-2}\right)$} \\
\hline & $22-37$ & $49-65$ & $65-80$ & $80-135$ & $22-37$ & $49-65$ & $22-37$ & $49-65$ & $22-37$ & $49-65$ & $22-37$ & $49-65$ \\
\hline Adonis & 0.186 & 0.064 & 0.055 & 0.019 & 13.8 & 9.1 & 136 & 77 & 0.641 & 0.332 & 4.73 & 4.32 \\
\hline WZ 64-5 & 0.190 & 0.085 & 0.037 & 0.021 & 13.9 & 11.6 & 137 & 83 & 0.647 & 0.342 & 4.71 & 4.17 \\
\hline TK 6126 & 0.190 & 0.074 & 0.040 & 0.017 & 14.6 & 12.6 & 130 & 68 & 0.627 & 0.305 & 4.84 & 4.56 \\
\hline TK 1937 & 0.200 & 0.088 & 0.045 & 0.020 & 13.3 & 12.2 & 152 & 81 & 0.632 & 0.347 & 4.22 & 4.30 \\
\hline Bastion & 0.189 & 0.082 & 0.039 & 0.016 & 13.9 & 13.5 & 137 & 70 & 0.626 & 0.294 & 4.59 & 4.22 \\
\hline Ralle & 0.172 & 0.077 & 0.050 & 0.018 & 12.7 & 12.4 & 135 & 71 & 0.629 & 0.314 & 4.67 & 4.52 \\
\hline Arkas & 0.176 & 0.077 & 0.047 & 0.017 & 13.0 & 11.2 & 135 & 78 & 0.609 & 0.325 & 4.53 & 4.20 \\
\hline Gaby & 0.174 & 0.090 & 0.040 & 0.021 & 12.2 & 11.0 & 142 & 93 & 0.669 & 0.384 & 4.72 & 4.20 \\
\hline Ceb. 7857 & 0.191 & 0.078 & 0.043 & 0.021 & 14.5 & 12.6 & 132 & 70 & 0.643 & 0.336 & 4.87 & 4.85 \\
\hline Ceb. 7958 & 0.192 & 0.083 & 0.047 & 0.020 & 13.2 & 10.2 & 145 & 91 & 0.679 & 0.402 & 4.69 & 4.45 \\
\hline Selpek & 0.178 & 0.085 & 0.046 & 0.022 & 12.8 & 11.6 & 140 & 82 & 0.663 & 0.370 & 4.77 & 4.53 \\
\hline Sicco & 0.197 & 0.082 & 0.051 & 0.022 & 13.6 & 10.1 & 145 & 92 & 0.661 & 0.368 & 4.55 & 4.02 \\
\hline Mean & 0.186 & 0.080 & 0.045 & 0.019 & 13.5 & 11.5 & 139 & 80 & 0.644 & 0.343 & 4.66 & 4.36 \\
\hline $\mathrm{SE}$ & 0.0059 & 0.0049 & 0.0049 & 0.0010 & 0.43 & 0.85 & 1.9 & 2.1 & 0.0053 & 0.0080 & 0.063 & 0.058 \\
\hline $\mathrm{CV}_{\mathrm{g}}$ & 0.039 & 0.060 & 0.049 & 0.092 & 0.042 & 0.081 & 0.042 & 0.108 & 0.031 & 0.092 & 0.034 & 0.051 \\
\hline
\end{tabular}


Order of magnitude for the genetic variation in RGR and its components

Difficulties in estimating the variation among genotypes. An order of magnitude for the genetic variation in the different growth components may be derived from the presented data and from the literature. Those data should be interpreted with care.

(a) In many publications genotype means are given without their respective standard errors. Estimating the genetic variation as the variation among genotype means and neglecting their error variance, causes an upward bias. This holds especially for RGR and NAR as these are subject to a large error variation. In our experiments (Table $3,4)$ the coefficient of variation based on varietal means of RGR overestimated the real genetic variation with on average $80 \%$.

(b) The variation among genotypes changes in course of ontogeny. The genetic coefficient of variation of RGR increased from about $5 \%$ during early growth to $10 \%$ during maturation (Fig. 4 in SPITTERs \& KrAMER, 1985), suggesting an increase of the relative variation among genotypes with plant development.

(c) The genetic variation among genotypes is also affected by the environment, with the coefficient of variation probably being smaller under more optimum growing conditions. The small and non-significant variation of only $1 \%$ for RGR with the same set of cultivars in the glasshouse (Table 4) may, apart from the very early growth stage involved (point b), be due to optimum conditions in the glasshouse. That under more favourable conditions differences between genotypes tend to become smaller is supported by an experiment with 12 genotypes of maize grown by DuNCAN \& HesKETH (1968) at different temperatures in controlled glasshouses. The coefficient of variation between genotype means for RGR of leaf area was for the two extreme daytime temperatures of 15 and $35^{\circ} \mathrm{C}$ on the average $18 \%$ against only $9 \%$ for the 5 intermediate temperatures. Data of MACDOWALL (1974) for 6 wheat varieties showed a less pronounced effect: $11 \%$ at $2-4{ }^{\circ} \mathrm{C}$ against $8 \%$ at $25^{\circ} \mathrm{C}$.

(d)In several papers, genotypes were used with a much more diverse origin than the ones occurring in breeding nurseries.

On the basis of the literature and our experimental results, orders of magnitude will be derived for the variation among genotypes in RGR and its components. This variation is quantified by the genetic coefficient of variation $\left(\mathrm{CV}_{\mathrm{g}}\right)$. Because of the four difficulties mentioned above, we could average the available information in a subjective way only. The presented estimates are expected to be representative for the vegetative growth stages of cereal genotypes occurring in breeding nurseries.

For the genetic coefficient of variation of the relative growth rate a value of 3-10\% seems realistic for the early stages of development. This order of magnitude is based on our experiments and on the results of Kranz (1966), Evans \& Dunstone (1970), Khan \& Tsunoda (1970a, b), Macdowall (1974), Elias \& Chadwick (1979), BurDON \& HARPER (1980), HunT \& EVANS (1980), and MAHON (1983).

Net assimilation rate is the outcome of gross assimilation minus respiration (Equation 5). In young plants, roughly $5 \%$ of the assimilated carbohydrates are used for maintenance respiration and a fraction of about $0.30\left(=1-\mathrm{E}_{\mathrm{c}}\right)$ of the weight of the remaining carbohydrates is lost as $\mathrm{CO}_{2}$ and $\mathrm{H}_{2} \mathrm{O}$ in the conversion to structural plant weight ( growth respiration). There is probably very little genetic variation in the conversion efficiency $E_{c}$ as this factor is directly related to the chemical composition of the produced biomass (PENNING DE VRIES et al., 1974), which composition is quite 
Table 4. Relative growth rate, net assimilation rate, leaf area ratio, leaf weight ratio, and specific leaf weight, all with respect to the aboveground parts, and shoot/root ratio for each of 12 spring wheat cultivars averaged over the harvests at day 7,11,16 and 21 after emergence. Plants were grown in a glasshouse at an average day/night temperature of $23 / 16^{\circ} \mathrm{C}$ during April and May 1980. Average global radiation at plant level was $13.4 \mathrm{MJ} \mathrm{m}^{-2} \mathrm{~d}^{-1}$.

\begin{tabular}{lllllll}
\hline & $\begin{array}{l}\text { RGR } \\
\text { day }\end{array}$ & $\begin{array}{l}\text { NAR } \\
\mathrm{g} \mathrm{m}^{-2} \mathrm{~d}^{-1}\end{array}$ & $\begin{array}{l}\text { LAR } \\
\mathrm{cm}^{2} \mathrm{~g}^{-1}\end{array}$ & $\begin{array}{l}\text { LWR } \\
\mathrm{g} \mathrm{g}^{-1}\end{array}$ & $\begin{array}{l}\text { SLW } \\
\mathrm{mg} \mathrm{cm}^{-2}\end{array}$ & $\begin{array}{l}\text { S/R } \\
\mathrm{g} \mathrm{g}^{-1}\end{array}$ \\
Adonis & 0.194 & 10.0 & 191 & 0.654 & 3.45 & 2.6 \\
WZ 64-5 & 0.199 & 10.4 & 188 & 0.654 & 3.51 & 3.6 \\
TK 6126 & 0.196 & 11.0 & 176 & 0.626 & 3.60 & 3.9 \\
TK 1937 & 0.198 & 10.3 & 189 & 0.656 & 3.52 & 3.5 \\
Bastion & 0.192 & 10.2 & 184 & 0.651 & 3.60 & 3.6 \\
Ralle & 0.191 & 10.5 & 179 & 0.646 & 3.64 & 3.9 \\
Arkas & 0.186 & 10.0 & 184 & 0.637 & 3.49 & 3.7 \\
Gaby & 0.192 & 10.0 & 189 & 0.670 & 3.57 & 3.3 \\
Geb. 7857 & 0.178 & 10.0 & 176 & 0.666 & 3.80 & 3.3 \\
Ceb. 7958 & 0.192 & 10.3 & 184 & 0.687 & 3.78 & 3.2 \\
Selpek & 0.202 & 10.4 & 191 & 0.659 & 3.46 & 3.5 \\
Sicco & 0.204 & 10.3 & 194 & 0.666 & 3.49 & 3.9 \\
Mean & 0.194 & 10.3 & 185 & 0.656 & 3.57 & 3.5 \\
SE & 0.013 & 0.34 & 3.8 & 0.0076 & 0.070 & 0.26 \\
CV & 0 & 0.025 & 0.021 & 0.026 & 0.072 \\
\hline
\end{tabular}

constant among genotypes in the vegetative phase and grown in the same environment. For maintenance respiration substantial genetic differences can be expected. First, plants with a greater leaf weight ratio will show a smaller plant maintenance respiration per unit leaf area because their cost of maintenance is divided by a relatively greater leaf area (Equation 10). Secondly, substantial differences among genotypes are demonstrated for the maintenance requirement of leaves (mean value of $0.015 \mathrm{~g} \mathrm{CH}_{2} \mathrm{O} \mathrm{g}^{-1}$ dry weight $\mathrm{d}^{-1}$ at $15^{\circ} \mathrm{C}$ in Equation 10), as indicated by the variation in leaf dark respiration reported in the literature. WILSON (1975) found a $\mathrm{CV}_{\mathrm{g}}$ of $21 \%$ for leaf dark respiration in perennial ryegrass and a $\mathrm{CV}_{\mathrm{g}}$ of $24 \%$ was measured by PENNING DE VRIES (pers. commun.) in tomato. Also VolenEC et al., (1984), in tall fescue, recorded significant variation in leaf dark respiration. However, as maintenance respiration has in the early stages only a minor contribution to NAR, the genetic variation in NAR in these early stages is mainly due to variation in gross assimilation. Photorespiration is part of gross assimilation so that a possible variation in photorespiration is hidden within the variation in gross assimilation.

The relationship between rate of gross $\mathrm{CO}_{2}$ assimilation of single leaves and absorbed light intensity is characterized by two quantities: the assimilation rate at light saturation $\left(\mathrm{A}_{\max }\right)$ and the efficiency at low light ( $(\varepsilon)$ (Equation 9). We start with the variation for assimilation rate of single leaves at light saturation. A very extensive data set on this is that of APEL \& LeHMANN (1969) who studied 108 genotypes of spring barley. From their results a genetic coefficient of variation of $9 \%$ can be estimated. We consider a range of $5-10 \%$ to be realistic for genotypes in breeding nurseries. This estimate is based on $\mathrm{CO}_{2}$ assimilation measurements of single leaves at high light published by Duncan \& Hesketh (1968), Pearce et al., (1969), Evans \& Dunstone 
(1970), Khan \& Tsunoda (1970a, 1971), Criswell \& Shibles (1971), Dantuma (1973), Asay et al. (1974), Kishitani \& TsUNOda (1974), Fischer et al. (1981), Austin et al. (1982), Mahon (1983), Evans et al. (1984), and Yamauchi \& Yoshida (1985). Values of $A_{\max }$ change with conditions for growth during leaf development and with leaf age. Genotypic differences for ageing pattern of leaf photosynthesis may be of greater significance than the usually recorded peak value of young, full-grown leaves. This is illustrated by the findings of Rawson et al. (1983) who measured leaf photosynthesis in 136 wheat lines. Peak flag leaf photosynthetic rate was not significantly related to grain yield of the main shoot, whereas this yield showed a highly significant correlation with rate of ageing of the flag leaf and with cumulated $\mathrm{CO}_{2}$ fixation by the flag leaf during its life. For a further discussion on perspectives and limitations of selection for high leaf assimilation rates see GIFFORD \& JENKINs (1982), RAwson et al., (1983) and WILSON (1984).

Differences between genotypes in $\mathrm{CO}_{2}$ assimilation are mainly due to the differences at high light $\left(\mathrm{A}_{\max }\right)$, whereas there appears to be little genetic variation for the initial light-utilization efficiency $\varepsilon$ when expressed per unit of absorbed light (e.g. Evans \& Dunstone, 1970; Buörkman, 1981; Ehleringer \& PeArCy, 1983). Because leaves do not photosynthesize all day long at saturation intensities, differences between genotypes in $\mathrm{A}_{\max }$ are reflected only partly in differences in actual assimilation rate (Equation 9) and with that in NAR. An other implication of the substantial variation in $A_{\max }$ with negligible variation in $\varepsilon$ is that genetic differences in NAR become smaller with a greater LAI because shading of leaves reduces their mean illumination intensity.

A greater assimilation rate per unit leaf area is attained also with a greater light absorption per unit leaf area, i.e. with a higher extinction coefficient (Equation 6). To a high extinction coefficient contribute a prostrate plant habit, minimization of self-shading, and low leaf reflectance and transmission. We measured light absorption at May 12 and 25 and June 5 in monocultures of the different cultivars grown at $10 \times 10 \mathrm{~cm}^{2}$ plant $^{-1}$. No significant differences were detected among these cultivars which all were of a rather similar habit. Evans et al. (1984), however, found substantial variation in extinction coefficient among rice varieties ( $\mathrm{k}$ varied from 0.3 to 0.6$)$. Greater assimilation at higher values of $\mathrm{k}$ holds only for isolated plants and sparse stands (about LAI < 3). For greater values of LAI, light interception is almost complete so that then just a smaller $k$ enhances the assimilation rate because of a more equal distribution of the light flux over the leaves.

The genetic variation for leaf area ratio was in the field experiment of the same magnitude as that for NAR (Table 1). This correspondence did not hold for the glasshouse experiment (Table 4). Also the results published by KHAN \& TsunODA. (1970a, b) suggest that in general the genetic variation for LAR is somewhat higher than that for NAR. The variation between genotypes for LWR seems to be of similar size as that for SLW or SLA (Table 1, 3; KHAN \& TsUNODA, 1970a, b).

Orders of magnitude of the genetic coefficients of variation for the growth parameters are summarized in Table 1 . We consider these indicative for the vegetative growth stages of cereal genotypes occurring in breeding nurseries. A $95 \%$ range is obtained as $4 \mathrm{CV}_{\mathrm{g}}$. Literature data suggest that $\mathrm{CV}_{\mathrm{g}}$ of genotypes with a very diverse origin is roughly twice the value applying to conventional breeding nurseries.

The influence on RGR of a change in any of the growth parameters can be evaluated 
by the presented growth model. Improving the light interception per plant looks more promising in increasing RGR of isolated plants than improving assimilation and respiration characteristics.

A breeding program for RGR on the basis of selection and recombination of the separate growth components looks attractive. One should, however, be aware of the compensation mechanisms, i.e. the negative correlations between the components. For instance, unrestricted selection for a high $A_{\max }$ might even reduce $R G R$ because of its negative relation with SLA.

\section{Applications in breeding practice}

Plant growth analysis in terms of RGR and its components is useful with respect to isolated plants and genotypes growing in mixture. Application in breeding practice can be derived from this.

(a) Selection in absence of interplant competition. Selection in isolation favours those genotypes showing a high RGR. We have discussed and quantified this aspect in the preceding paper. In the present one, the genetic differences in RGR were partitioned into those of its components. In a forthcoming paper, it will be discussed to how far types selected in isolation are also the types giving the highest yield in monoculture.

(b) Selection from a mixed, segregating population. The percentage differences in plant weight between genotypes in mixture are maintained in time if the genotypes have an equal RGR. Deviations from this constancy in rank are, by definition, the result of differences in RGR (SPITTERS, 1984a). Growth analysis demonstrates which types possess a higher RGR and are therefore favoured by selection from a mixed, segregating population. It shows also the size of the genetic variation in RGR and with that to how far differences in final biomass in mixture are due to differences in RGR or to differences in initial size (Equation 6 given in SPITTERS \& KRAMER, 1985). It must be noted that the differences between genotypes in RGR in a closespaced mixture deviate from those in isolation (genotype $\times$ spacing interaction), especially because of the differences in light climate between both spacings and the quite synchronous ripening in closed stands.

(c) Selection for rapid juvenile growth to attain earlier canopy closure and therefore higher yield in monoculture. Time of canopy closure is estimated approximately as the time that the growth rate in the exponential phase becomes equal to that in the linear phase of a closed crop. Hence

$$
\mathrm{y}_{\mathrm{o}} \cdot \overline{\mathrm{RGR}} \cdot \mathrm{e}^{\overline{\mathrm{RGK}} \cdot \mathrm{t}_{\mathrm{c}}}=\mathrm{P} \text { or } \mathrm{t}_{\mathrm{c}}=\frac{1}{\overline{\mathrm{RGR}}} \ln \frac{\mathrm{P}}{\mathrm{y}_{\mathrm{o}} \cdot \overline{\mathrm{RGR}}}
$$

where $t_{c}$ is time of canopy closure in days after emergence, $\overline{R G R}$ is the mean relative growth rate before $t_{c}, y_{o}$ is the initial biomass per unit area at emergence and is roughly half of the weight of the seeds sown, and $P$ is the growth rate of the closed canopy under the prevailing conditions. Initial biomass $y_{o}$ is the product of weight per seedling and number of seedlings per unit area. With such an approach, genetic variation in onset of canopy closure can be partitioned into different components and the expected response for selection of each of the components separately can be quantified. In the experiment discussed, differences in seed size between the genotypes had the greatest effect. 
The expected advantage of earlier canopy closure is not more than about $200 \mathrm{~kg}$ biomass per hectare for each day that the canopy closes earlier as this value is the potential growth rate for a green, closed canopy under optimum conditions (SIBMA, 1968). In small cereals the advantage will in general be small. That is illustrated by the many experiments where cereal crops grown from large seeds gave only a slight yield benefit or no benefit at all over crops grown from small seeds (e.g. VAN DoBBEN, 1966). The perspectives are however greater for crops starting with a low initial weight like sugar beet and maize (SiBMA, 1977).

\section{REFERENCES}

APEL, P. \& C. O. LeHMANN, 1969. Variabilität und Sortenspezifität der Photosyntheserate bei Sommergerste. Photosynthetica 3: 255-262.

ASAY, K. H., C. J. Nelson \& G. L. HoRST, 1974. Genetic variability for net photosynthesis in tall fescue. Crop Sci. 14: 571-574.

Austin, R. B., C. L. Morgan, M. A. Ford \& S. G. Bhagwat, 1982. Flag leaf photosynthesis of Triticum aestivum and related diploid and tetraploid species. Ann. Bot. 49: 177-189.

BJöRKMAN, O., 1981. Responses to different quantum flux densities. Encyclopedia of plant physiology, New Series 12A: 57-107. Springer, Berlin.

Burdon, J. J. \& J. L. HARPER, 1980. Relative growth rates of individual members of a plant population. J. Ecol. 68: 953-957.

Causton, D. R. \& J. C. Venus, 1981. The biometry of plant growth. Edward Arnold, London, $307 \mathrm{pp}$.

Criswell, J. G. \& R. M. Shibles, 1971. Physiological basis for genotypic variation in net photosynthesis of oat leaves. Crop Sci. 11: 550-553.

Dantuma, G., 1973. Rates of photosynthesis in leaves of wheat and barley varieties. Neth. J. agric. Sci. 21: $188-198$.

DobBen, W. H. van, 1966. Systems of management of cereals for improved yield and quality. In F. L. Milthorpe \& J. D. IVins (Eds), The growth of cereals and grasses. Butterworths, London, pp. 320-334.

DunCAN, W. G. \& J. D. Hesketh, 1968. Net photosynthetic rates, relative leaf growth rates, and leaf numbers of 22 races of maize grown at eight temperatures. Crop Sci. 8: 670-674.

Ehleringer, J. \& R. W. PearCy, 1983. Variation in quantum yield for $\mathrm{CO}_{2}$ uptake among $\mathrm{C}_{3}$ and $\mathrm{C}_{4}$ plants. Plant Physiol. 73: 555-559.

Elias, C. O. \& M. J. Chadwick, 1979. Growth characteristics of grass and legume cultivars and their potential for land reclamation. J. appl. Ecol. 16: 537-544.

Evans, L. T. \& R. L. Dunstone, 1970. Some physiological aspects of evolution in wheat. Austr. J. biol. Sci. 23: 725-741.

Evans, L. T., R. M. Visperas \& B. S. Vergara, 1984. Morphological and physiological changes among rice varieties used in the Philippines over the last seventy years. Field Crops Res. 8: 105-124.

Fischer, R. A., F. Bidinger, J. R. Syme \& P. C. Wall, 1981. Leaf photosynthesis, leaf permeability, crop growth, and yield of short spring wheat genotypes under irrigation. Crop Sci. 21: 367-373.

Gerwen, C. P. van, C. J. T. Spitters \& G. M. J. Mohren, 1986. Simulation of competition for light in even-aged stands of Douglas fir. Submitted to For. Ecol. Manage.

Gifford, R. M. \& C. L. D. Jenkins, 1982. Prospects of applying knowledge of photosynthesis toward improving crop production. In: GovinDJEe (Ed.), Photosynthesis: development, carbon metabolism, and plant productivity, Vol. II. Academic Press, New York, p. 419-457.

Goudriann, J,, 1982. Potential production processes. In: F. W. T. Penning de Vries \& H. H. Van LaAR (Eds), Simulation of plant growth and crop production, pp. 98-113. Simulation Monograph, Wageningen, Pudoc.

Hunt, R., 1982. Plant growth curves. Edward Arnold, London, 248 pp.

Hunt, R. \& G. C. Evans, 1980. Classical data on the growth of maize: curve fitting with statistical analysis. New Phytol. 86: 155-180.

HunT, R. \& I. T. PARsons, 1977. Plant growth analysis: further applications of a recent curve-fitting program. J. appl. Ecol. 14: 965-968. 
KISHITANI, S. \& S. TsUNODA, 1974. Effect of low and high temperature pretreatment on leaf photosynthesis and transpiration in cultivars of Oryza sativa. Photosynthetica 8: 161-167.

KHAN, M. A. \& S. TsunODA, 1970a. Leaf photosynthesis and transpiration under different levels of air flow rate and light intensity in cultivated wheat species and its wild relatives. Jap. J. Breeding 20: 305-314.

KHAN, M. A. \& S. TSUNODA, 1970b. Growth analysis of six commercially cultivated wheats of West Pakistan with special reference to a semi-dwarf modern wheat variety, Mexi-Pak. Tohoku J. agric. Res. 21: 60-72.

KHAN, M. A. \& S. TsUNODA, 1971. Comparative leaf anatomy of cultivated wheats and wild relatives with reference to their leaf photosynthetic rates. Jap. J. Breeding 21: 143-150.

KranZ, A. R., 1966. Stoffproduktion und Assimilationsleistung in der Evolution der Kulturpflanzen. II. Versuchsergebnisse und zusammenfassende Diskussion. Biol. Zentralblatt 85: 681-734.

MACDOWALL, F. D. H., 1974. Growth kinetics of Marquis wheat. VI. Genetic dependence and winter hardening. Can. J. Bot. 52: 151-157.

MAHON, J. D., 1983. Limitations to the use of physiological variability in plant breeding. Can. J. Plant Sci. 63: $11-21$.

Plarcli, R. B., G. E. Carlson, D. K. Barnes, R. H. Hart \& C. H. Hanson, 1969. Specific leaf weight and photosynthesis in alfalfa. Crop Sci. 9: 423-426.

Penning de Vries, F. W. T., A. H. M. Brunsting \& H. H. van Laar, 1974. Products, requirements and efficiency of biosynthesis: a quantitative approach. J. theor. Biol. 45: 339-337.

Penning de VRies, F. W. T. \& H. H. van LaAR, 1982. Simulation of growth processes and the model Bacros. In: F. W. T. Penning de Vries \& H. H. van LaAr (Eds), Simulation of plant growth and crop production, pp. 114-135. Simulation Monograph, Wageningen: Pudoc.

RADFORD, P. J., 1967. Growth analysis formulae - their use and abuse. Crop Sci. 7: 171-175.

Rawson, H. M., J. H. Hindmarsh, R. A. Fischer \& Y. M. Stockman, 1983. Changes in leaf photosynthesis with plant ontogeny and relationships with yield per ear in wheat cultivars and 120 progeny. Austr. J. Pl. Physiol. 10: 503-514.

SiвmA, L., 1968. Growth of closed green crop surfaces in the Netherlands. Neth. J. agric. Sci. 16: 211-216.

Sibma, L., 1977. Maximization of arable crop yields in the Netherlands. Neth. J. agric. Sci. 25: 278-287.

SPiTTERs, C. J. T., 1984a. Effects of intergenotypic competition on selection. In: W. LANGE, A. C. ZEVEN \& N. G. Hogenboom (Eds), Efficiency in plant breeding: Proc. 10th Congr. Europ. Ass. Res. P1. Breed., EUCARPIA. Pudoc, Wageningen, pp. 13-27.

SpiTters, C. J. T., 1984b. A simple simulation model for crop-weed competition. 7th Int. Symp. Weed Biology, Ecology and Systematics. COLUMA (Comité Français de Lutte contre les Mauvaises Herbes) - EWRS (European Weed Research Society), Paris, pp. 355-366.

SpitTers, C. J. T. \& TH. Kramer, 1985. Changes in relative growth rate with plant ontogeny in spring wheat genotypes grown as isolated plants. Euphytica 34: 833-847.

Volenec, J. J., H. T. NGuyen, C. J. Nelson \& D. A. Sleper, 1984. Potential for genetically modifying dark respiration of tall fescue leaves. Crop Sci. 24: 938-943.

WiLson, D., 1975. Variation in leaf respiration in relation to growth and photosynthesis of Lolium. Ann. appl. Biol. 80: 323-338.

Wilson, D., 1984. Development of better selection criteria. In: W. LANGE, A. C. ZEven \& N. G. HooGENBOOM (Eds), Efficiency in plant breeding: Proc. 10th Congr. Europ. Ass. Res. P1. Breed., EUCARPIA. Pudoc, Wageningen, pp. 117-129.

YAMAUCHI, M. \& S. YoShIDA, 1985. Heteroses in net photosynthetic rate, leaf area, tillering, and some physiological characters of $35 \mathrm{~F}_{1}$ rice hybrids. J. exp. Bot. 36: 274-280.

Zadoks, J. C., T. T. Chang \& C. F. KonZAK, 1974. A decimal code for the growth stages of cereals. Eucarpia Bull. 7: 42-52. 
APPENDIX

This appendix contains tables with primary data for weight per seed, time to seedling and ear emergence, weather statistics, dry weight (W), specific leaf weight (SLW), leaf weight ratio (LWR), ear weight ratio (EWR) and harvest index (HI) of the 12 spring wheat varieties used in the experiment. Data are for plants in isolation. Time is given in days after seedling emergence, except for seedling emergence itself. Average time of emergence was April 16. Plants of the harvests at day 16,22, 28, 37 and 43 were grown at 15 $\times 15 \mathrm{~cm}^{2}$ plant $^{-1}$, those of the harvests at day $34,49,65$ and 80 at $20 \times 40 \mathrm{~cm}^{2}$ plant ${ }^{-1}$ and for the final harvest (day 135) a spacing of $40 \times 40 \mathrm{~cm}^{2}$ plant ${ }^{-1}$ was used.

Average growth stages according to ZADOKS et al. (1974) are 11 (day 16), 22 (day 28), 30 (day 34), 33 (day 37), 37 (day 43), 65 (day 68) and 91 (day 135).

Table A. Weight per seed and dates of seedling and ear emergence of the 12 varieties.

\begin{tabular}{lllll}
\hline Variety & $\begin{array}{l}\text { Weight }{ }^{1} \text { per } \\
\text { seed }(\mathrm{mg})\end{array}$ & $\begin{array}{l}\text { Time of } 50 \% \\
\text { seedling emergence } \\
\text { (in days after sowing) }\end{array}$ & $\begin{array}{l}\text { Time of } 50 \% \\
\text { ear emergence }\end{array}$ & $\begin{array}{l}\text { Time of } 50 \% \\
\text { anthesis }\end{array}$ \\
Adonis & 46.7 & 15.37 & 62.3 & 67.3 \\
WZ 64-5 & 38.5 & 14.85 & 61.5 & 65.4 \\
TK 6126 & 46.5 & 15.32 & 61.0 & 64.1 \\
TK 1937 & 43.1 & 15.63 & 63.8 & 68.1 \\
Bastion & 40.9 & 15.16 & 60.8 & 66.2 \\
Ralle & 49.2 & 14.39 & 63.5 & 68.7 \\
Arkas & 39.9 & 15.36 & 62.8 & 67.1 \\
Gaby & 33.4 & 15.50 & 64.3 & 70.8 \\
Ceb. 7857 & 39.3 & 14.43 & 63.8 & 71.1 \\
Ceb. 7958 & 43.1 & 15.65 & 64.0 & 71.4 \\
Selpek & 41.8 & 15.59 & 64.3 & 69.0 \\
Sicco & 39.6 & 14.82 & 63.5 & 68.2 \\
mean & 41.8 & 15.17 & 63.0 & 0.352 \\
SE & 0.63 & 0.271 & 0.254 & \\
\hline
\end{tabular}

${ }^{1} 92 \%$ dry matter.

Table B. Weather conditions during the 1980 growing season at Wageningen.

\begin{tabular}{|c|c|c|c|c|c|}
\hline \multirow[t]{2}{*}{ Month } & \multirow[t]{2}{*}{ Decade } & \multicolumn{2}{|c|}{ Mean daily temp. $\left({ }^{\circ} \mathrm{C}\right)$} & \multirow{2}{*}{$\begin{array}{l}\text { Rainfall } \\
(\mathrm{mm})\end{array}$} & \multirow{2}{*}{$\begin{array}{l}\text { Mean total } \\
\text { global radiation } \\
\left(\mathrm{J} \mathrm{cm}^{-2} \mathrm{~d}^{-1}\right)\end{array}$} \\
\hline & & $\max$. & $\min$. & & \\
\hline \multirow[t]{2}{*}{ April } & 2 & 16.2 & 3.2 & 9.4 & 1691 \\
\hline & 3 & 11.5 & 1.6 & 4.9 & 1270 \\
\hline \multirow[t]{3}{*}{ May } & 1 & 14.8 & 3.8 & 2.9 & 2055 \\
\hline & 2 & 21.5 & 6.0 & 0.5 & 2437 \\
\hline & 3 & 17.3 & 5.6 & 5.9 & 2001 \\
\hline \multirow[t]{3}{*}{ June } & 1 & 21.6 & 8.3 & 21.1 & 1757 \\
\hline & 2 & 21.3 & 11.9 & 17.9 & 1563 \\
\hline & 3 & 16.6 & 8.7 & 27.5 & 1560 \\
\hline \multirow[t]{3}{*}{ July } & 1 & 17.7 & 11.7 & 82.7 & 1154 \\
\hline & 2 & 16.6 & 10.8 & 59.1 & 1000 \\
\hline & 3 & 23.4 & 12.5 & 3.9 & 2095 \\
\hline \multirow[t]{3}{*}{ August } & 1 & 23.5 & 13.4 & 4.0 & 1642 \\
\hline & 2 & 22.1 & 14.7 & 14.0 & 1254 \\
\hline & 3 & 18.7 & 9.2 & 28.4 & 1328 \\
\hline September & 1 & 19.7 & 10.4 & 6.8 & 1343 \\
\hline
\end{tabular}


EARLY GROWTH OF WHEAT

Table C. Dry weight per plant at various moments during the growing period for the 12 varieties.

\begin{tabular}{|c|c|c|c|c|c|c|c|c|c|c|}
\hline \multirow[t]{2}{*}{ Variety } & \multicolumn{10}{|c|}{$\mathrm{W}\left(\mathrm{g} \mathrm{pl}^{-1}\right)$} \\
\hline & 16 & 22 & 28 & 34 & 37 & 43 & 49 & 65 & 80 & 135 \\
\hline Adonis & 0.0214 & $0.0497^{\mathrm{ab}} *$ & $0.124^{\mathrm{b}}$ & $0.533^{\mathrm{bc}}$ & $0.698^{\mathrm{abcd}}$ & $1.26^{\mathrm{ab}}$ & $4.08^{b c}$ & $11.6^{\mathrm{b}}$ & $26.5^{b c}$ & $75.9^{\mathrm{cd}}$ \\
\hline WZ 64-5 & 0.0229 & $0.0555^{\mathrm{ab}}$ & $0.117^{b}$ & $0.614^{b}$ & $0.788^{\mathrm{ab}}$ & $1.28^{a b}$ & $3.59^{b c}$ & $13.7^{\mathrm{ab}}$ & $23.9^{\mathrm{c}}$ & $74.3^{\mathrm{cd}}$ \\
\hline TK 6126 & 0.0276 & $0.0640^{\mathrm{a}}$ & $0.137^{b}$ & $0.753^{\mathrm{a}}$ & $0.860^{a}$ & $1.68^{\mathrm{a}}$ & $5.40^{\mathrm{a}}$ & $17.7^{\mathrm{a}}$ & $32.2^{a b}$ & $82.9^{b c}$ \\
\hline TK 1937 & 0.0212 & $0.0424^{b}$ & $0.111^{b}$ & $0.608^{b}$ & $0.682^{a b c d}$ & $1.04^{b}$ & $3.68^{\mathrm{bc}}$ & $14.9^{\mathrm{ab}}$ & $29.2^{\mathrm{abc}}$ & $85.8^{\mathrm{ab}}$ \\
\hline Bastion & 0.0214 & $0.0518^{\mathrm{ab}}$ & $0.129^{b}$ & $0.540^{\mathrm{bc}}$ & $0.779^{\mathrm{ab}}$ & $1.45^{\mathrm{ab}}$ & $4.33^{b c}$ & $16.2^{\mathrm{ab}}$ & $29.0^{\mathrm{abc}}$ & $69.2^{\mathrm{cd}}$ \\
\hline Ralle & 0.0291 & $0.0650^{a}$ & $0.184^{\mathrm{a}}$ & $0.563^{b c}$ & $0.819^{a b}$ & $1.52^{\mathrm{ab}}$ & $4.72^{a b}$ & $16.2^{\mathrm{ab}}$ & $34.0^{\mathrm{a}}$ & $89.9^{a b}$ \\
\hline Arkas & 0.0185 & $0.0492^{\mathrm{ab}}$ & $0.123^{b}$ & $0.526^{\mathrm{bc}}$ & $0.563^{\mathrm{cd}}$ & $1.12^{\mathrm{ab}}$ & $3.84^{\mathrm{bc}}$ & $13.5^{\mathrm{ab}}$ & $26.6^{\mathrm{bc}}$ & $69.1^{\mathrm{cd}}$ \\
\hline Gaby & 0.0199 & $0.0454^{\mathrm{b}}$ & $0.088^{b}$ & $0.443^{\mathrm{c}}$ & $0.510^{\mathrm{d}}$ & $1.19^{a b}$ & $3.50^{\mathrm{c}}$ & $14.6^{\mathrm{ab}}$ & $26.9^{\mathrm{bc}}$ & $82.6^{b c}$ \\
\hline Ceb. 7857 & 0.0233 & $0.0522^{\mathrm{ab}}$ & $0.123^{b}$ & $0.657^{b}$ & $0.704^{a b c d}$ & $1.17^{\mathrm{ab}}$ & $4.10^{b c}$ & $14.2^{\mathrm{ab}}$ & $27.1^{b c}$ & $85.1^{b c}$ \\
\hline Ceb. 7958 & 0.0230 & $0.0484^{\mathrm{ab}}$ & $0.133^{b}$ & $0.609^{b}$ & $0.717^{\mathrm{abc}}$ & $1.34^{\mathrm{ab}}$ & $3.39^{\mathrm{c}}$ & $12.9^{\mathrm{ab}}$ & $26.2^{\mathrm{bc}}$ & $77.2^{\mathrm{cd}}$ \\
\hline Selpek & 0.0224 & $0.0534^{\mathrm{ab}}$ & $0.102^{b}$ & $0.508^{b c}$ & $0.616^{\text {bed }}$ & $1.31^{\mathrm{ab}}$ & $3.69^{b c}$ & $14.4^{a b}$ & $28.8^{a b c}$ & $98.1^{\text {at }}$ \\
\hline Sicco & 0.0205 & $0.0460^{b}$ & $0.122^{b}$ & $0.602^{b}$ & $0.722^{a b c}$ & $1.00^{\mathrm{b}}$ & $3.71^{b c}$ & $13.7^{\mathrm{ab}}$ & $29.6^{\mathrm{abc}}$ & $97.9^{a}$ \\
\hline mean & 0.0226 & 0.0519 & 0.125 & 0.580 & 0.705 & 1.28 & 4.00 & 14.5 & 28.3 & 82.3 \\
\hline SE & - & 0.00366 & 0.0118 & 0.0312 & 0.0526 & 0.127 & 0.236 & 0.99 & 1.35 & 2.68 \\
\hline $\mathrm{df}$ & - & 33 & 33 & 22 & 33 & 33 & 22 & 22 & 51 & 403 \\
\hline
\end{tabular}

* Values followed by the same letter are not significantly different in the Student-Newman-Keuls test at $P \leqslant 0.05$.

Table D. Specific leaf weight (SLW) at various moments during the growing period for the 12 varieties. SLW was determined for green leaf blades.

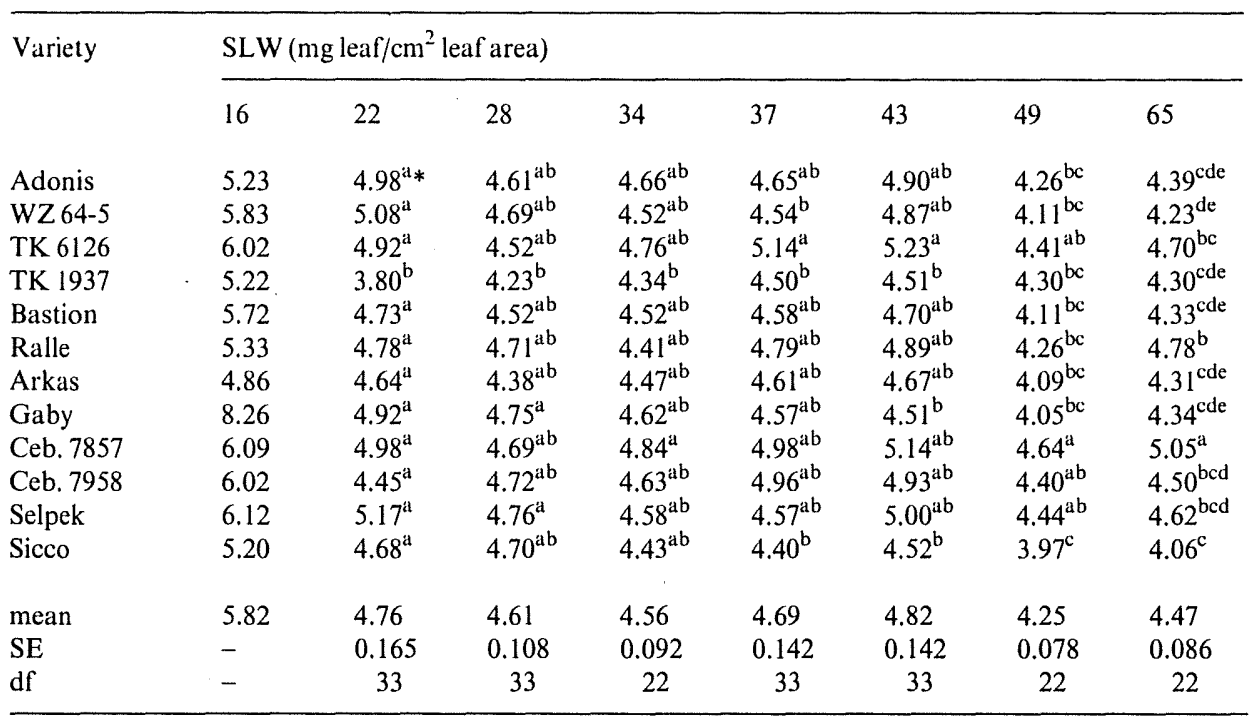

* Values followed by the same letter are not significantly different in the Student-Newman-Keuls test at $P \leqslant 0.05$.

Euphytica 35 (1986) 


\section{J. T. SPITTERS AND TH. KRAMER}

Table E. Leaf weight ratio (LWR), ear weight ratio (EWR) at various moments during the growing period and harvest index (HI) at maturity. LWR was determined for green leaf blades.

\begin{tabular}{|c|c|c|c|c|c|c|c|c|c|c|}
\hline \multirow[t]{2}{*}{ Variety } & \multicolumn{7}{|c|}{ LWR (g leaf/g plant) } & \multicolumn{2}{|c|}{ EWR (ं gear/g plant) } & \multirow{2}{*}{$\frac{\mathrm{HI}}{135}$} \\
\hline & 22 & 28 & 34 & 37 & 43 & 49 & 65 & 65 & 80 & \\
\hline Adonis & $0.689^{\mathrm{a} *}$ & $0.674^{\mathrm{abc}}$ & $0.626^{a b c}$ & $0.573^{\mathrm{d}}$ & $0.535^{\mathrm{abc}}$ & $0.428^{\text {de }}$ & $0.237^{\mathrm{bc}}$ & $0.127^{\mathrm{b}}$ & $0.208^{\text {cde }}$ & $0.403^{\text {bcd }}$ \\
\hline WZ 64-5 & $0.712^{\mathrm{a}}$ & $0.689^{a b c}$ & $0.600^{\text {bcd }}$ & $0.587^{\mathrm{cd}}$ & $0.526^{\mathrm{abc}}$ & $0.458^{\text {bcde }}$ & $0.227^{\text {bcd }}$ & $0.171^{\mathrm{ab}}$ & $0.247^{\mathrm{b}}$ & $0.438^{\mathrm{a}}$ \\
\hline TK $6126^{* *}$ & $0.704^{a}$ & $0.643^{\mathrm{c}}$ & $0.595^{\text {bcd }}$ & $0.565^{\mathrm{de}}$ & $0.500^{b c}$ & $0.418^{\mathrm{de}}$ & $0.192^{d}$ & $0.223^{a}$ & $0.277^{\mathrm{a}}$ & $0.415^{\mathrm{abc}}$ \\
\hline TK 1937** & $0.684^{a}$ & $0.668^{a b c}$ & $0.593^{b c d}$ & $0.582^{\mathrm{cd}}$ & $0.568^{\mathrm{a}}$ & $0.457^{\text {bcde }}$ & $0.238^{b c}$ & $0.191^{\mathrm{a}}$ & $0.240^{\mathrm{bc}}$ & $0.425^{\mathrm{ab}}$ \\
\hline Bastion & $0.691^{\mathrm{a}}$ & $0.662^{b c}$ & $0.588^{\mathrm{cd}}$ & $0.564^{\mathrm{de}}$ & $0.500^{b c}$ & $0.398^{\mathrm{e}}$ & $0.189^{d}$ & $0.168^{\mathrm{ab}}$ & $0.230^{\mathrm{bcd}}$ & $0.393^{\text {cde }}$ \\
\hline Ralle & $0.675^{\mathrm{a}}$ & $0.668^{a b c}$ & $0.600^{\text {bed }}$ & $0.574^{\mathrm{d}}$ & $0.518^{\mathrm{abc}}$ & $0.416^{\mathrm{de}}$ & $0.212^{\mathrm{cd}}$ & $0.167^{\mathrm{ab}}$ & $0.205^{\mathrm{cde}}$ & $0.368^{\mathrm{ef}}$ \\
\hline Arkas & $0.671^{\mathrm{a}}$ & $0.644^{\mathrm{c}}$ & $0.574^{\mathrm{d}}$ & $0.564^{\mathrm{e}}$ & $0.562^{\mathrm{ab}}$ & $0.432^{\text {cde }}$ & $0.218^{\mathrm{cd}}$ & $0.168^{\mathrm{ab}}$ & $0.231^{\mathrm{bcd}}$ & $0.390^{\text {cde }}$ \\
\hline Gaby & $0.711^{\mathrm{a}}$ & $0.699^{\mathrm{ab}}$ & $0.646^{\mathrm{a}}$ & $0.617^{a b}$ & $0.570^{\mathrm{a}}$ & $0.504^{\mathrm{ab}}$ & $0.265^{\mathrm{ab}}$ & $0.112^{\mathrm{b}}$ & $0.184^{\mathrm{e}}$ & $0.369^{\mathrm{ef}}$ \\
\hline Ceb. $7857^{* *}$ & $0.701^{\mathrm{a}}$ & $0.672^{\mathrm{abc}}$ & $0.619^{a b c}$ & $0.579^{\mathrm{cd}}$ & $0.497^{\mathrm{c}}$ & $0.450^{\text {bcde }}$ & $0.221^{\mathrm{cd}}$ & $0.167^{\mathrm{ab}}$ & $0.229^{\mathrm{bcd}}$ & $0.392^{\text {cde }}$ \\
\hline Ceb. 7958 & $0.718^{a}$ & $0.712^{\mathrm{a}}$ & $0.650^{\mathrm{a}}$ & $0.636^{a}$ & $0.560^{\mathrm{abc}}$ & $0.524^{\mathrm{a}}$ & $0.281^{\mathrm{a}}$ & $0.119^{b}$ & $0.204^{\text {cde }}$ & $0.385^{\mathrm{de}}$ \\
\hline Selpek & $0.684^{\mathrm{a}}$ & $0.699^{\mathrm{ab}}$ & $0.640^{\mathrm{a}}$ & $0.630^{\mathrm{a}}$ & $0.555^{\mathrm{abc}}$ & $0.478^{a b c d}$ & $0.261^{\mathrm{ab}}$ & $0.108^{b}$ & $0.191^{\mathrm{de}}$ & $0.352^{\Upsilon}$ \\
\hline Sicco & $0.716^{\mathrm{a}}$ & $0.695^{\mathrm{ab}}$ & $0.632^{\mathrm{ab}}$ & $0.601^{b c}$ & $0.557^{\mathrm{abc}}$ & $0.488^{a b c}$ & $0.246^{a b c}$ & $0.114^{\mathrm{b}}$ & $0.194^{\text {de }}$ & $0.393^{\text {cde }}$ \\
\hline mean & 0.696 & 0.677 & 0.614 & 0.588 & 0.537 & 0.454 & 0.232 & 0.153 & 0.220 & 0.394 \\
\hline $\mathrm{SE}$ & 0.0150 & 0.0103 & 0.0085 & 0.0074 & 0.0135 & 0.0133 & 0.0090 & 0.0130 & 0.0091 & 0.0055 \\
\hline df & 33 & 33 & 22 & 33 & 33 & 22 & 22 & 22 & 51 & 403 \\
\hline
\end{tabular}

* Values followed by the same letter are not significantly different in the Student-Newman-Keuls test at $P \leqslant 0.05$.

** Genotypes with awned ears. 